\title{
Erratum to: Mitigating Foundation Settlement Induced by Tunnel Construction
}

\author{
Mona Badr El-Din Anwar ${ }^{(凶)}$ \\ Civil Engineering Department, The German University in Cairo, \\ New Cairo, Egypt \\ mona.anwar@guc.edu.eg
}

\section{Erratum to: \\ Chapter "Mitigating Foundation Settlement Induced by Tunnel Construction" in: S. Agaiby and P. Grasso (eds.), Engineering Challenges for Sustainable Underground Use, Sustainable Civil Infrastructures, DOI 10.1007/978-3-319-61636-0_15}

In the original version of this book, the author's second affiliation has to be deleted in Chapter 15, which is a belated correction. The erratum chapter and the book have been updated with the change. 